\title{
Catastrophic failure planning for the SR 520 bridge
}

\author{
G. MacDonald ${ }^{1}$, D. Babuca ${ }^{2}$, A. Swanson ${ }^{3}$, T. Lentz ${ }^{4}$ \& P. Scalingi ${ }^{5}$ \\ ${ }^{1}$ Parametrix, Bremerton, Washington, USA \\ ${ }^{2}$ Washington Department of Transportation, Seattle, Washington, USA \\ ${ }^{3}$ EnviroIssues, Seattle, Washington, USA \\ ${ }^{4}$ Parsons Brinckerhoff, Seattle, Washington, USA \\ ${ }^{5}$ Pacific NorthWest Economic Region, Seattle, Washington, USA
}

\begin{abstract}
The State Route 520/Evergreen Point Floating in Seattle, Washington, is vulnerable to windstorms and earthquakes and needs to be replaced. The Washington State Department of Transportation (WSDOT) recognizes the need to have a plan in place to manage traffic and communications if the SR 520 floating bridge were lost in such an event. The plan was developed in collaboration with regional jurisdictions, transit agencies, emergency responders, and businesses, as a toolkit of strategies that could be implemented quickly and effectively to benefit the region. WSDOT also invited engineers from Minnesota DOT to contribute to the plan by sharing their experience from I-35W bridge collapse and recovery. The main components of the plan are the Transportation Management Plan and the Communications Plan. A regional tabletop exercise focusing on a SR 520 catastrophic failure scenario helped to inform the development of the plan. The SR 520 Catastrophic Failure Plan provides a basis for WSDOT to prepare for a catastrophic bridge failure and for local jurisdictions to develop their own emergency response plans.
\end{abstract}

Keywords: catastrophic failure plan, transportation management, communication, tabletop exercise, floating bridge, disaster preparation, bridge failure. 


\section{Introduction}

Seattle, Washington is bounded by the Puget Sound on the west and Lake Washington on the east. State Route 520 (SR 520) is one of only two east-west links across Lake Washington and is a vital regional transportation corridor of both people and goods. The SR 520 floating bridge currently carries approximately 160,000 people and 115,000 vehicles per day [1]. Construction of SR 520 was completed in 1963 and touts the world's longest floating bridge. The aging SR 520 bridge and approaches are vulnerable to both windstorms and earthquakes, and are nearing the end of their useful lives [2]. If the SR 520 bridge were to fail, the effects to regional and statewide travel and economy would be significant.

The Washington State Department of Transportation (WSDOT) is committed to catastrophic failure planning to ensure public safety and a speedy recovery in the event of a catastrophic loss of the SR 520 bridge. In coordination with transportation, communications and emergency response professionals from regional jurisdictions, transit agencies, businesses and community organizations, WSDOT has developed a catastrophic plan to lay out steps state and local agencies may take to manage traffic and communications should such an event occur. The plan consists of a transportation management plan and a communications plan [3].

\subsection{Keeping the Seattle Regional Area moving}

The overarching goal of the catastrophic failure plan is to identify strategies to keep people and commerce moving in and around the Seattle and surrounding cities (also known as the central Puget Sound region) in the event of a SR 520 bridge failure. The catastrophic failure plan builds upon established WSDOT SR 520 emergency management procedures. It represents a toolbox of strategies that can be implemented to keep central Puget Sound drivers and commerce moving during a long-term recovery from a SR 520 bridge failure.

The transportation management plan provides WSDOT, local jurisdictions and transit agencies with transportation strategies designed to ease traffic congestion resulting from the failure of the SR 520 bridge. The communications plan will support emergency response, bridge recovery and bridge restoration efforts through development, coordination and dissemination of emergency public information. See Figure 1 for the focus area for the SR 520 bridge catastrophic planning efforts. The figure also identifies the jurisdictions that coordinated with WSDOT during the planning.

\subsection{Current WSDOT activities that support the catastrophic failure plan}

WSDOT is currently in the process of the design and construction of a replacement bridge and adjoining highway segments. The purpose of the SR 520 Bridge Replacement and HOV Project is to increase safety and reliability of the highway and bridge. Elements of the SR 520 Bridge Replacement and HOV Project support the catastrophic failure plan. These include: 
- SR 520 Pontoon Construction Project-This project advances pontoon construction in hopes of restoring the floating section of the SR 520 bridge before a catastrophic failure event occurs.

- Accelerated SR 520 project schedule - In response to the Washington State Governor's request, WSDOT identified ways to shorten the overall project schedule. The acceleration will result in opening the new bridge to traffic in 2014. This will result in closing the window of vulnerability for a potential catastrophic failure.

\subsection{Developing the catastrophic failure plan}

The SR 520 Bridge Replacement and HOV Project team continued to work with jurisdictions and transit agencies to facilitate a coordinated response to a potential SR 520 bridge failure. The intent was to develop a comprehensive list of potential strategies and improvements for WSDOT highway facilities that could get the central Puget Sound region moving again and could aid in the longterm recovery process. The SR 520 project team developed a three-pronged approach to prepare a catastrophic failure plan:

- Conduct a tabletop exercise.

- Develop a transportation management plan.

- Develop a communications plan.

In a final step, the transportation management plan and the communications plan were merged into the catastrophic failure plan.

\section{Tabletop exercise and action strategy workshop}

The SR 520 project team prepared plans for a tabletop exercise that would help inform a catastrophic failure plan. The resulting transportation management plan and communications plan seek to address findings of the tabletop exercise action strategy workshop.

\subsection{Tabletop exercise}

WSDOT hosted a day-long tabletop exercise with local jurisdictions, businesses and other key stakeholder organizations to examine preparedness, response and longer-term recovery issues associated with a SR 520 bridge failure. The goals of the exercise were to:

- Raise awareness of vulnerabilities and risks to the bridge.

- Identify response and longer-term restoration needs in the event of a SR 520 bridge failure.

- Develop "lessons-learned" that could be incorporated into future plans and activities addressing longer-term consequences and challenges associated with the resilience of the regional economy and moving people and freight.

- Obtain information from participants that could be used to develop a transportation management plan and a communications plan to be implemented in the event of a SR 520 bridge failure. 


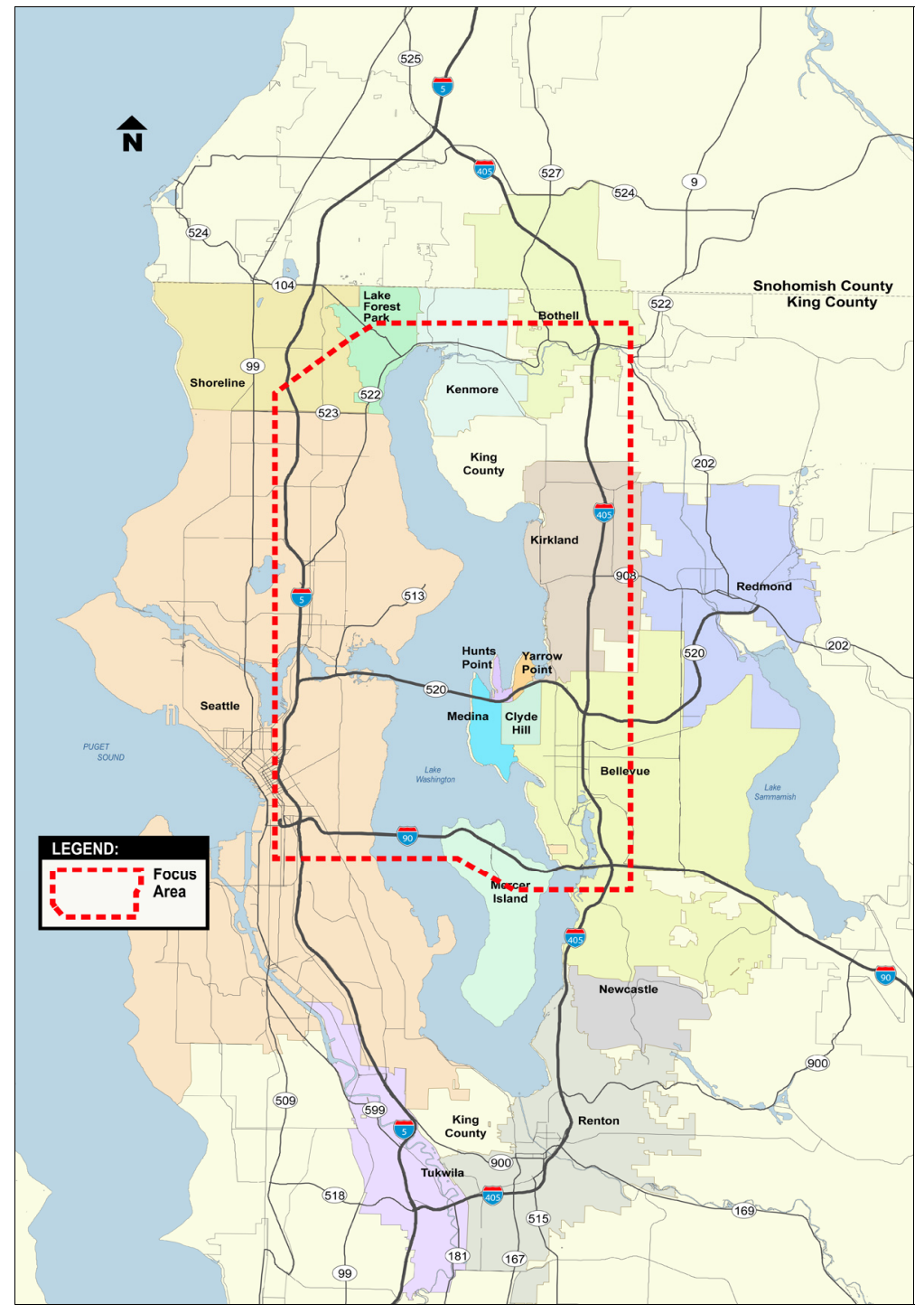

Figure 1: $\quad$ Focus area and coordinating jurisdictions.

\subsection{Action strategy workshop}

Tabletop exercise participants met for a follow-up action strategy workshop. The goal of the workshop was to discuss and prioritize transportation management activities on the basis of findings and recommendations from the tabletop exercise. Specific action strategies were developed in the areas of communications, emergency management, economic issues, freight issues, and mobility. 


\section{Transportation management plan}

\subsection{Bridge failure scenario}

Of the failure scenarios considered during preliminary catastrophic failure planning, the final transportation management plan assumed only a windstormcaused loss of the SR 520 bridge. In this scenario, it was assumed that the approach structures would remain operational.

An earthquake scenario could result in significantly more infrastructure damage than just the SR 520 bridge and its approaches, possibly affecting other regional structures. Because of the broad-scale damage that could result from such a disaster, evaluation of an earthquake scenario was determined to be beyond the scope of the transportation management plan. However, most of the conclusions and recommendations outlined in the plan - while focused on the loss of the SR 520 floating bridge structure only - are intended to be useful in a variety of bridge failure and other emergency scenarios.

\subsection{WSDOT's priorities for managing regional highway facilities in the event of a SR 520 bridge failure}

The strategies described in the transportation management plan were developed to move people and goods as safely and efficiently as possible in the event of a SR 520 bridge failure. Given the already congested highway system, a transit and transportation demand management response will be vital to keeping traffic moving on the regional highway system. This approach allows movement of the most people in the fewest number of vehicles. Therefore, the roadway improvements described here were identified to prioritize efficient transit and high occupancy vehicle (HOV) travel, and to maintain reliability and travel time as much as possible without compromising safety.

\subsection{Evaluated facilities}

The SR 520 project team reviewed the results from the SR 520 travel demand model used during preliminary catastrophic failure planning which estimated potential changes in traffic patterns with the loss of the SR 520 bridge. Based on these results and additional analysis, the project team focused its analysis on state routes that would be expected to carry the majority of the displaced bridge traffic (Figures 2 and 3). A broader area was evaluated for the transit component of the transportation management plan, which included a review and evaluation of service and infrastructure improvements beyond WSDOT facilities. Review elements included locations for more bus stops, park-and-ride facilities and transit centers.

\subsection{Key outreach participants}

The SR 520 project team met with transportation managers and public information officers from local jurisdictions in a series of meetings. These 
meetings were important because they allowed jurisdictional staff to share their respective concerns and to collaborate on the development of initial transportation management and communications strategies. The SR 520 project team worked with the local Jurisdictions, transit agencies, and WSDOT Public Transportation and Freight Systems Divisions throughout the transportation management plan development process.

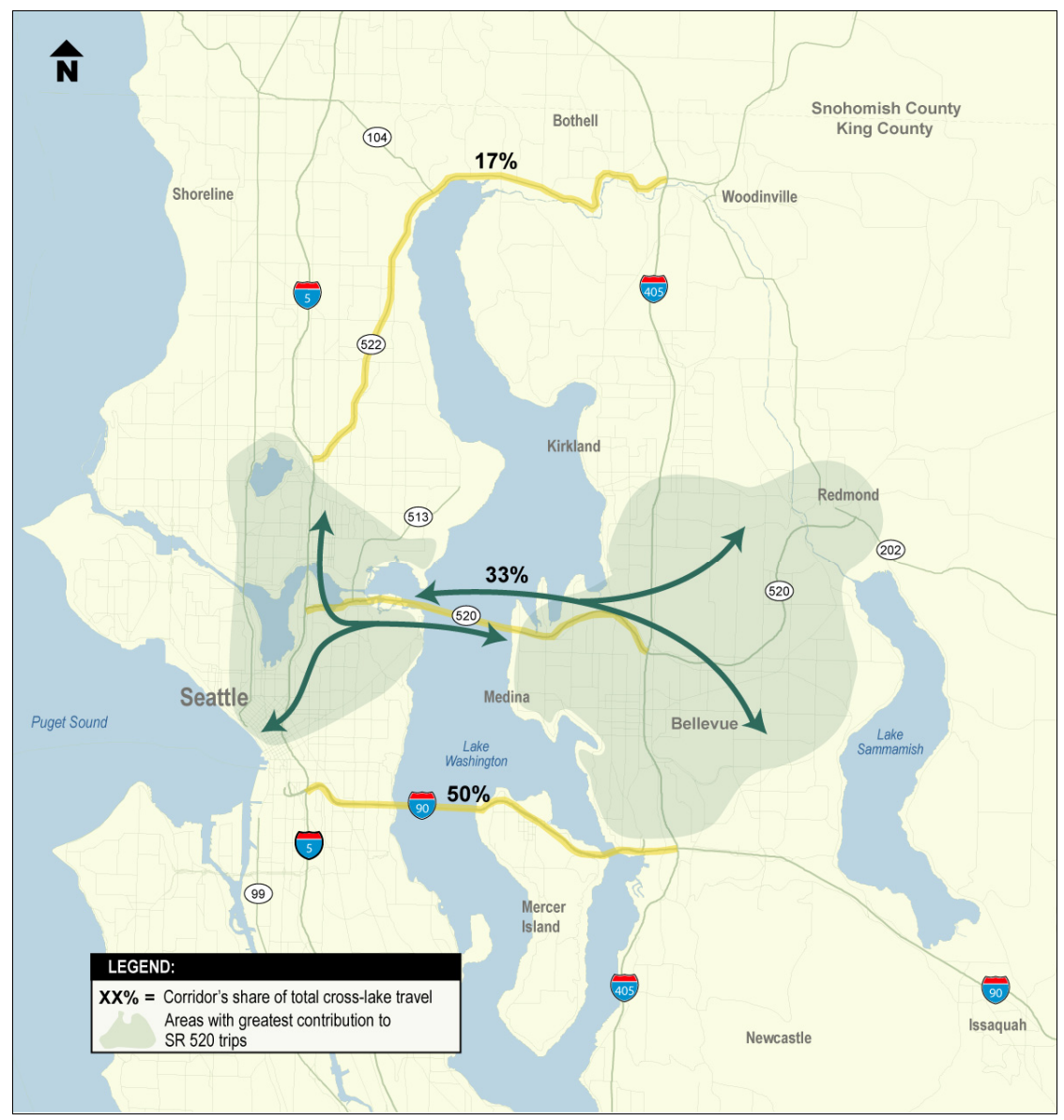

Figure 2: Current cross-lake Washington traffic patterns [4].

\subsection{Key transportation management strategies}

In the event of a SR 520 bridge failure, WSDOT will act quickly to ensure the maximum safety and efficiency of the regional highway system. Detailed response strategies and transportation demand management tactics listed in the transportation management plan describe how WSDOT will approach this. 


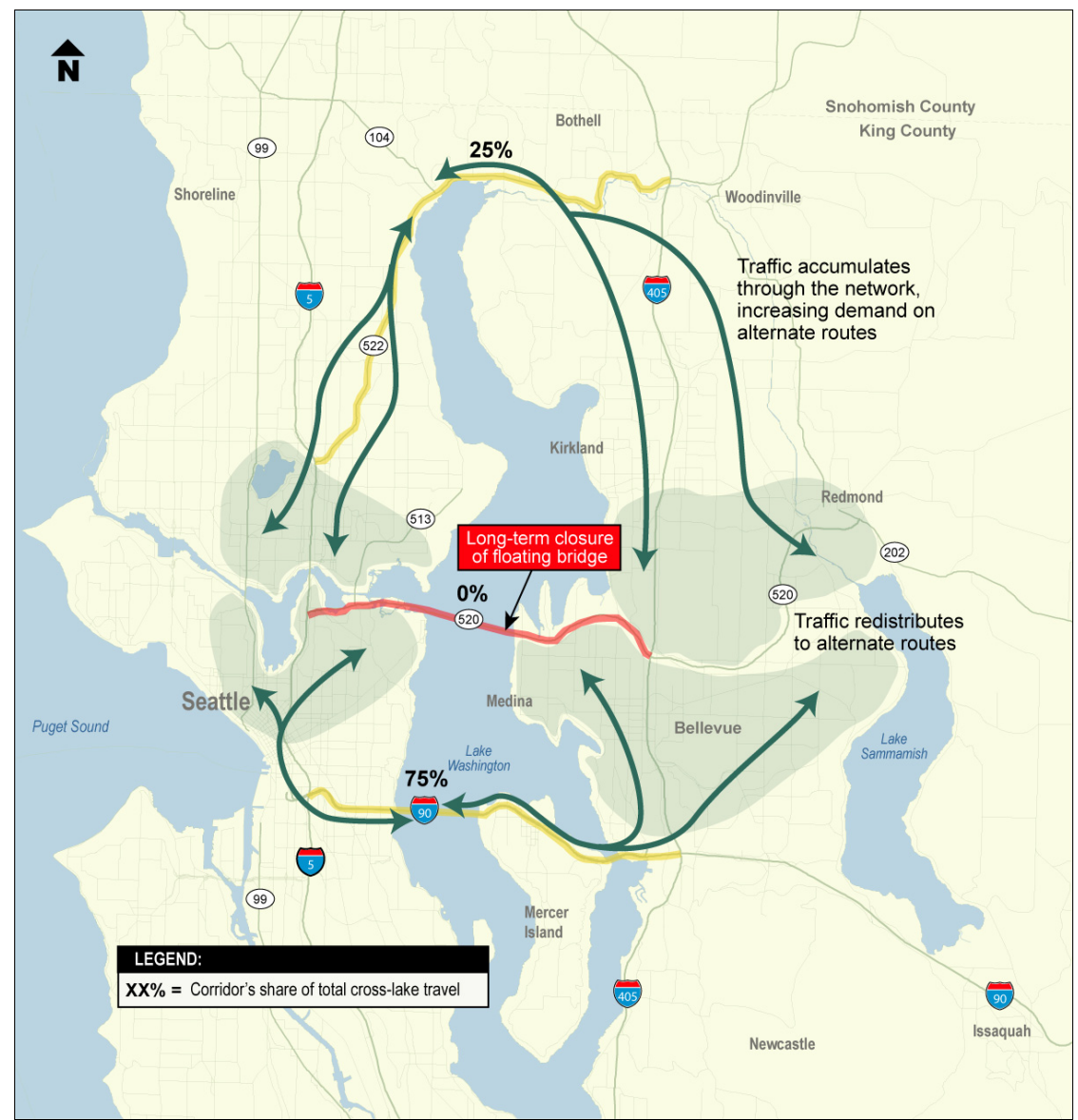

Figure 3: Projected cross-lake Washington traffic patterns following a SR 520 bridge failure [4].

\subsubsection{Strategies for the central Puget Sound region's major corridors}

The transportation management plan further details a series of suggested transportation management packages that could be implemented as first steps to keep the region moving after a SR 520 bridge failure. These packages are intended to be used as an initial starting point for traffic mitigation. They can be implemented within one month of a catastrophic bridge failure; other packages described in the transportation management plan are designed for implementation within a longer timeframe.

Some of the packages are temporary in nature and are intended to be in service under emergency conditions while the SR 520 structures are being replaced. Design standards, such as speed and lane width, would be evaluated when implementing the temporary strategies to determine whether design deviations should be considered. Some of the packages build upon plans that are 
already in design or are programmed for construction. In the event of a SR 520 bridge failure, WSDOT would determine which of these projects would be accelerated or delayed based on the changed traffic conditions. Recommended strategies or packages are to be quickly implemented on one of the region's key transportation corridors after a catastrophic bridge failure: SR 520, I-90, I-5, SR 522, SR 523, and I-405.

\subsubsection{Transit agencies' role in addressing mobility}

In the event of a SR 520 bridge failure, transit service would play a key role in maintaining mobility throughout the region, particularly across Lake Washington. There are three major considerations regarding the role of transit agencies in addressing mobility following a SR 520 bridge failure:

- Transit will need fast and reliable paths to be an effective transportation mode, requiring commitment to transit priority.

- Public awareness and rider incentives will be needed to ensure that people take maximum advantage of available transit service.

- Availability of equipment, personnel and particularly funding will constrain how quickly new transit service can be added and the total amount of additional transit service that will be possible.

Modifications to transit service following a SR 520 bridge failure includes discussion of how service would likely be modified to provide connections between major centers on the west and east sides of Lake Washington. Rider incentives Strategies should also include increasing the effectiveness.

\subsubsection{Managing transportation demand}

Transportation demand management (TDM) uses existing infrastructure as efficiently as possible and implements programs to reduce demand for transportation facilities. In the event of a SR 520 bridge failure, it will be critical to make the best use of the available infrastructure by increasing the use of alternative travel modes and work arrangements.

TDM strategies such as expanded employer-sponsored commuter benefits programs and new demonstration programs are also part of the transportation management plan.

\subsubsection{Freight considerations}

For freight traffic, returning traffic operations to as close to pre-failure conditions as soon as possible will be critical. This is consistent with the transportation management plan goal of maintaining reliability and travel times. Towards this end, the planned regional projects and recommended traffic management strategies focus on improving overall traffic operations on regional freeway systems in the event of a SR 520 bridge failure. While many of the recommended improvements would benefit freight movement, the transportation management plan does not provide specific strategies for improving freight movement in the event of a bridge failure. Such strategies would require regional policy deliberations and additional coordination with local agencies that were not part of the scope of this planning effort. 


\subsection{Transportation management next steps}

The transportation management plan provides a starting point in identifying a range of possible strategies to manage the regional transportation system in the event of a SR 520 bridge failure. The plan suggests a process for implementing appropriate strategies in a timely manner following a bridge failure. It also suggests early actions and strategies that could be advanced to enhance regional preparedness.

\section{Communications plan}

To prepare for a possible SR 520 bridge failure, the WSDOT, in collaboration with regional jurisdictions and agencies, has developed a communications plan. In the event of a bridge failure, the plan will support emergency response, bridge recovery and bridge restoration efforts through development, coordination and dissemination of emergency public information.

The plan will serve as a guide for WSDOT communicators to use if a catastrophic failure were to occur. The plan builds on current communications strategies that have been implemented when unplanned, short-term closures have occurred in the past (e.g., during several recent winter windstorms) and identifies specific tools and strategies to utilize if SR 520 is closed for a longer period of time.

\subsection{Purpose}

Emphasizing public safety is WSDOT's first priority in the event of a SR 520 bridge failure. Also important is to ensure public confidence in WSDOT as a credible and accountable organization. The communications plan should provide effective guidelines, strategies and tools for WSDOT communications staff in the event of a SR 520 bridge failure. The plan outlines suggested guidelines, strategies and tools for jurisdictions and agencies to effectively disseminate critical, core information to their constituencies. It also establishes clear and effective communication lines between WSDOT and local, regional, state and, if needed, federal personnel while providing a communications framework that ensures consistent messaging across agencies.

\subsection{Assumptions}

\subsubsection{Incident command system and emergency operations centers}

In the event of a SR 520 bridge failure, it is assumed that the incident command system, under the National Incident Management System, would be utilized. It is also assumed that the emergency operations center at WSDOT's Northwest Region Dayton office in Shoreline would be activated. It is also likely that other state and regional emergency operations centers would activate, depending on the event severity and its regional effects. 


\subsubsection{Bridge failure scenario}

The communications plan does not specify a particular SR 520 bridge failure scenario. It assumes that the strategies and tools identified may be universally applied in any medium- to long-term closure of the SR 520 corridor, including the Evergreen Point floating bridge, the Portage Bay viaduct, and the surrounding roadways or approaches. In either an earthquake or severe windstorm event, it is assumed that a failure of SR 520 would be part of a larger regional situation. Viewing simulated visualizations of how the SR 520 bridge could fail in either an earthquake [5] or a windstorm [6] assisted the public to understand the vulnerabilities of the floating bridge, and gave a sense of realism to the failure scenario.

\subsubsection{Timeframe}

The communications plan outlines activities and strategies for different phases of a potential catastrophic failure: pre-storm, the response phase, and the recovery and restoration phase. The official transition between the response and the restoration occurs when the incident command post is dismantled.

\subsection{Key players and resources}

WSDOT is the lead agency in communicating and disseminating information about the SR 520 bridge. WSDOT will work closely with King County and local municipalities and assist with other regional transportation agencies. WSDOT will rely on a variety of communications outlets and resources to help communicate messages during a SR 520 closure. These resources include: the WSDOT Web site; 5-1-1 CARS hotline system; television, radio and print media; regional Public Information Network (www.rpin.org); Northwest Warning, Alert, Response Network (NW-WARN www.nwwarn.org); other regional, state and local emergency operations centers; and public information officers and communications staff from coordinating jurisdictions and agencies.

\subsection{Communication strategies}

The following key strategies will be implemented during a SR 520 closure: no surprises, coordinate messaging, manage expectations, lead with the Web, utilize the 5-1-1 CARS hotline system, establish innovative means of communication when power and telephone lines are out, choose spokespeople strategically, and show and tell the response and recovery story.

\subsection{Objectives}

WSDOT's overall objectives for communications during a catastrophic event will be to provide information to travelers, freight, neighbors and others who are affected so they can make informed decisions; keep public trust; and to minimize on-scene disruptions during the immediate response and recovery phases to allow emergency responders to do their work effectively. 


\subsection{Key audiences}

In the immediate response phase, and when the SR 520 bridge is closed during the recovery phase, there are many key audiences to be considered. Due to the regional significance of SR 520, the critical audiences are broad and widereaching. They include: emergency service providers; local, regional, state and federal transportation decision-makers; media; transit agencies; utilities; local jurisdictions, neighbors and community organizations; drivers and commuters; freight carriers; school districts and higher education institutions; businesses and employers; traditionally under-represented and special needs groups; tribal nations; and regulatory agencies.

\section{Conclusion}

WSDOT already has established SR 520 emergency management procedures with current SR 520 traffic control plans. Also there is a WSDOT bridge inspection manual which documents the procedures for closing the SR 520 bridge during emergencies and non-emergencies [7]. WSDOT Northwest Region prepared a guide for SR 520 bridge closures that identifies traffic control plans and provides suggestions for operating highway advisory radio and variable message signs during such closures [8]. The catastrophic failure plan goes a step further. It represents a toolbox of strategies that can be implemented to keep central Puget Sound drivers and commerce moving during a long-term recovery from a SR 520 bridge failure.

The catastrophic failure plan, composed of a transportation management plan and a communications plan, outlines options to ensure safety, efficiency and effective public relations in the event of a SR 520 bridge failure. The transportation management plan describes practical traffic mitigation solutions to keep Puget Sound moving in the event of a catastrophic SR 520 bridge failure.

Keeping drivers and transit riders informed about current roadway conditions and ongoing traffic restoration efforts will be essential to the success of this plan. To achieve this, WSDOT has also developed a communications plan. Communication will support emergency response, bridge recovery and bridge restoration efforts through the development, coordination and dissemination of emergency public information.

\section{References}

[1] Washington State Department of Transportation, WSDOT SDEIS, I-5 to Medina: Bridge Replacement and HOV Project, Supplemental Draft Environmental Impact Statement, Transportation Discipline Report, Part 2, pages 5-7, 2010

[2] WSDOT SDEIS [1], Executive Summary, page 4, 2010

[3] Washington State Department of Transportation, Catastrophic Failure Plan, 2008, http://www.wsdot.wa.gov/NR/rdonlyres/76E13051-8555-47B5AF0B-C0999DA5CB90/0/CFPExecSummary.pdf 
160 Disaster Management and Human Health Risk II

[4] Washington State Department of Transportation, SR 520 Bridge Replacement and HOV Program, EMME/2 Travel Demand Model, 2006.

[5] Washington State Department of Transportation, YouTube, WSDOT's Channel, SR 520 Floating Bridge - Simulated failure by earthquake, http://www.youtube.com/wsdot\#p/search/14/qIiuDUgvZpY

[6] Washington State Department of Transportation, YouTube, WSDOT's Channel, SR 520 Floating Bridge - Simulated failure by wind storm, http:/www.youtube.com/wsdot\#p/search/8/qchD91tCPG8

[7] Washington State Department of Transportation, WSDOT Operations, Inspection, and Maintenance Manual for the Evergreen Point Bridge, Area 5 Maintenance

[8] Washington State Department of Transportation, SR 520 Bridge Closure Guide, Area 5 Maintenance 